\title{
Mitochondrial dysfunction induces EMT through the TGF- $/$ /Smad/Snail signaling pathway in Hep3B hepatocellular carcinoma cells
}

\author{
EUI-YEUN YI ${ }^{1 *}$, SHI-YOUNG PARK ${ }^{2 *}$, SEUNG-YOUN JUNG ${ }^{3}$, WON-JUN JANG ${ }^{4}$ and YUNG-JIN KIM ${ }^{1}$ \\ ${ }^{1}$ Department of Molecular Biology, Pusan National University, Busan 609-735; ${ }^{2}$ Korea Mouse Metabolic \\ Phenotyping Center, Lee Gil Ya Cancer and Diabetes Institute, Gachon University School of Medicine, Incheon 406-840; \\ ${ }^{3}$ Department of Radiation Cancer Research, Korea Institute of Radiological and Medical Sciences, Seoul 139-706; \\ ${ }^{4}$ College of Pharmacy, Keimyung University, 1000 Sindang-Dong, Dalseo-Gu, Daegu 704-701, Republic of Korea
}

Received June 30, 2015; Accepted August 10, 2015

DOI: $10.3892 /$ ijo.2015.3154

\begin{abstract}
Mitochondrial dysfunction has been found to be associated with various pathological conditions, particularly cancer. However, the mechanisms underlying tumor malignancy induced by mitochondrial dysfunction are not fully understood. In the present study, the effects of mitochondrial dysfunction on epithelial-mesenchymal transition (EMT), were investigated using mitochondrial-depleted $\mathrm{Q}^{0}$ cells derived from the Hep3B hepatocarcinoma cell line. The Hep3B $/ \mathrm{Q}^{0}$ cells displayed the EMT phenotype with more aggressive migration and higher invasiveness compared to their parental cells. The Hep3B $/ \mathrm{Q}^{0}$ cells also showed typical expression pattern of EMT markers such as vimentin and E-cadherin. These phenotypes in Hep3B/ $Q^{0}$ cells were mediated by increased transforming growth factor- $\beta$ (TGF- $\beta$ ) through the canonical Smad-dependent signaling pathway. Additionally, TGF- $\beta$ signaling was activated via induction of c-Jun/AP-1 expression and activity. Therefore, mitochondrial dysfunction induces EMT through TGF- $\beta$ / Smad/Snail signaling via c-Jun/AP-1 activation. These results indicate that mitochondrial dysfunction plays an important role in the EMT process and could be a novel therapeutic target for malignant cancer therapy.
\end{abstract}

\section{Introduction}

Mitochondria are semi-autonomous intracellular organelles that play decisive roles in energy metabolism, regulation of programmed cell death, and free radical production (1). Mitochondrial dysfunction occurs due to mitochondrial DNA

Correspondence to: Professor Yung-Jin Kim, Department of Molecular Biology, College of Natural Science, Pusan National University, Busan 609-735, Republic of Korea

E-mail: yjinkim@pusan.ac.kr

*Contributed equally

Key words: AP-1, epithelial-mesenchymal transition, hepatocellular carcinoma, mitochondrial dysfunction, TGF- $\beta$
(mtDNA) damage and mutation, and is associated with aging. Recently, several studies have shown that mitochondrial defects can play an important role in the progression of cancer including hepatocellular carcinoma (HCC) (2-4). While there are reports of these phenomena, the mechanisms responsible for the initiation and evolution of mtDNA mutations, as well as their roles in the development of cancer remain to be elucidated.

HCC originates in hepatocytes or even in liver progenitor cells (5). In particular, epithelial hepatocytes are not proliferative under physiological conditions and have highly diverse functions. However, they have highly proliferative regeneration in response to partial hepatectomies and chemical intoxication (6). Various complicated mechanisms have been reported to cause abnormal proliferation and dedifferentiation of hepatocytes in HCC pathogenesis, which leads to the subsequent development of malignant tumors (7).

There is a critical point when epithelial cells exhibit phenotypes with abnormal proliferation, invasion and migration abilities, and drug resistance to malignant tumor treatment. This point is called the epithelial-mesenchymal transition (EMT). EMT represents the transition of epithelial cells to a mesenchymal phenotype, and it features a loss of epithelial cell markers (8). In adults, it has been revealed that EMT plays an important role in tumor formation and progression to metastatic carcinomas (9).

The mtDNA mutations leading to mitochondrial dysfunction are expected to play a substantial role in the EMT process. However, the details and molecular mechanisms underlying this phenomenon are still unclear. In the present study, Hep3B/ $\mathrm{Q}^{0}$ cells, which are mtDNA-depleted cells, were generated in order to investigate the role of mitochondrial dysfunction and its regulatory mechanisms in the EMT phenomenon. Using Hep3B $/ \mathrm{Q}^{0}$ cells, EMT properties and an associated signaling pathway in cells with mitochondrial dysfunction were investigated.

\section{Materials and methods}

Materials and reagents. Dulbecco's modified Eagle's medium (DMEM), fetal bovine serum (FBS), antibiotics (penicillin and 
streptomycin), 10 Trypsin/EDTA solution, and phosphate-buffered saline (PBS) were purchased from Welgen, Inc. (Daegu, Korea). Matrigel and $8-\mu \mathrm{m}$ pored Transwell filter chambers were purchased from Corning Inc. (Tewksbury, MA, USA). All oligo primers were generated from Cosmo Genetech Co., Ltd. (Seoul, Korea). The antibodies were purchased from the following suppliers: Cell Signaling Technology Inc. (Danvers, MA, USA), Santa Cruz Biotechnology Inc. (Dallas, TX, USA), and R\&D Systems Inc. (Minneapolis, MN, USA). SB431542 and c-Jun peptide were purchased from Tocris Bioscience (Ellisville, MO, USA). Alexa 488-conjugated secondary antibody and Fluo-4/AM were obtained from Invitrogen (Carlsbad, CA, USA).

Cell culture. Human hepatocellular carcinoma cells (Hep3B) were obtained from the Korean Cell Line Bank (Seoul, Korea). Hep3B cells were grown in high-glucose-DMEM supplemented with $10 \%$ FBS, 100 units/ml of penicillin, and $100 \mu \mathrm{g} / \mathrm{ml}$ of streptomycin in a $37^{\circ} \mathrm{C}$ incubator with a humidified atmosphere containing $5 \% \mathrm{CO}_{2}$.

Generation of Hep3B $/ \varrho^{0}$ cells. To develop Hep3B $/ \mathrm{Q}^{0}$ cells, Hep3B was chronically exposed to $50 \mathrm{ng} / \mathrm{ml}$ of $\mathrm{EtBr}$ in media supplemented with sodium pyruvate $(100 \mathrm{mM})$ and uridine (50 $\mu \mathrm{g} / \mathrm{ml})$. Subsequently, the Hep3B $/ \mathrm{Q}^{0}$ cell line was selected by treatment with media consisting of the mitochondrial inhibitors rotenone $(1 \mu \mathrm{g} / \mathrm{ml})$ and antimycin-A $(1 \mu \mathrm{g} / \mathrm{ml})$. After selection of the Hep3B $/ \mathrm{Q}^{0}$ cell line, the cells were grown in high glucose DMEM supplemented with $10 \% \mathrm{FBS}, 50 \mu \mathrm{g} / \mathrm{ml}$ of uridine and $100 \mathrm{mM}$ of sodium pyruvate.

Reverse transcription-polymerase chain reaction. Total RNA from the cells was isolated using TRIzol reagent (Invitrogen Corp.). First-strand cDNA was synthesized by M-MLV reverse transcriptase (Promega, Madison, WI, USA) with $1 \mu \mathrm{g}$ each of DNA-free total RNA sample and oligo-(dT)15 (Life Technologies, Grand Island, NY, USA). Equal amounts of cDNA were subsequently amplified by PCR in a $20-\mu 1$ reaction mixture containing $1 \mathrm{X}$ reaction buffer, $\mathrm{dNTP}$ mixture, $\mathrm{i}-\mathrm{Taq}^{\mathrm{TM}}$ DNA polymerase (iNtRON Biotechnology, Seongnam, Korea), and $10 \mu \mathrm{M}$ of each specific primer. Amplification products were electrophoresed on $1 \%$ agarose gel and visualized by GelRed (Biotium Inc., Hayward, CA, USA) staining under ultraviolet transillumination.

Electron microscopy. Cells grown on coverslips were fixed with a solution of $2.5 \%$ glutaraldehyde and $2 \%$ formaldehyde in $100 \mathrm{mM}$ cacodylate buffer $\left(\mathrm{pH} \mathrm{7.4)}\right.$ ) for $1.5 \mathrm{~h}$ at $4^{\circ} \mathrm{C}$, washed twice with cacodylate buffer, and were fixed with $2 \%$ osmium tetroxide in $50 \mathrm{mM}$ cacodylate buffer ( $\mathrm{pH} 7.4)$. Specimens were washed twice with distilled-water and stained overnight with aqueous $0.5 \%$ uranyl acetate at $4{ }^{\circ} \mathrm{C}$. Cells were dehydrated and flat embedded in Epon 812. Ultra-thin sections were analyzed with a Bio-TEM (Tecnai G2 Spirit; FEI Co., Hillsboro, OR, USA) at the Korea Basic Science Institute.

Assay for endogenous cellular oxygen consumption. Exponentially growing cells $\left(5 \times 10^{6}\right)$ of wild-type and Hep3B $/ \mathrm{Q}^{0}$ cells were washed with TD (Tris-based, $\mathrm{Mg}^{2+}-, \mathrm{Ca}^{2+}$-deficient) buffer $\left(0.137 \mathrm{mM} \mathrm{NaCl}, 5 \mathrm{mM} \mathrm{KCl}, 0.7 \mathrm{mM} \mathrm{Na}_{2} \mathrm{HPO}_{4}\right.$, and
$25 \mathrm{mM}$ Tris- $\mathrm{HCl}, \mathrm{pH}$ 7.4) and collected after trypsinization. After resuspending the cells $\left(5 \times 10^{5}\right)$ in $0.3 \mathrm{ml}$ of a complete medium without phenol red, the cells were transferred to a Mitocell chamber equipped with a Clark oxygen electrode (782 Oxygen Meter; Strathkelvin Instruments, Co., Motherwell, UK). Oxygen consumption rates were measured after adding $30 \mu \mathrm{M} 2$,4-dinitrophenol (DNP) to obtain a maximum respiration rate, and its specificity for mitochondrial respiration was confirmed by adding $5 \mathrm{mM}$ of potassium cyanide $(\mathrm{KCN})$. Maximum cellular respiration rates are expressed as the ratio of DNP-uncoupled $\mathrm{O}_{2}$ consumption rate vs. $\mathrm{KCN}$-inhibited $\mathrm{O}_{2}$ consumption rate.

In vitro wounding migration assay. The cells were plated on 24-well plates (Nunc, Rochester, NY, USA) at $90 \%$ confluence and left overnight. Cells were scratched with a P200 pipettetip. After wounding, the cultures were further incubated in media supplemented with $1 \%$ FBS. The cells were allowed to migrate for 16-24 h. Migration patterns were observed under a phase contrast microscope and photographed.

In vitro Transwell invasion assay. The invasion capacity of the cells was determined using a 24-well Transwell system. The upper side of the Transwell membrane was coated with $1 \mathrm{mg} / \mathrm{ml}$ Matrigel using $10 \mu \mathrm{l} /$ well. The cells were seeded at a density of $2 \times 10^{4}$ cells in $100 \mu \mathrm{l}$ of serum-free media to the upper compartment of the Transwell and the full medium was added to the lower side. Cells were incubated for 16-24 h at $37^{\circ} \mathrm{C}$ in $5 \% \mathrm{CO}_{2}$. Cells that did not penetrate the filter were wiped off with cotton swabs, and cells that had invaded the lower surface of the filter were fixed with methanol. The cells were then stained with hematoxylin/eosin, observed under a phase contrast microscope and photographed.

Immunofluorescence. Cells were plated with submerged coverslips. The primary antibodies used were mouse antiE-cadherin antibody and mouse anti-vimentin monoclonal antibody. The Alexa 488-conjugated secondary antibody was used for visualization of the primary antibodies. The nuclei were counterstained by $300 \mathrm{mM}$ of 4,6-diamidino-2-phenylindole (DAPI; Invitrogen). The coverslips were mounted onto glass slides with Vectastain (Vector Laboratories). The images were obtained with a fluorescence microscope (Nikon, Tokyo, Japan) and laser-scanning confocal microscope (LSM510; Carl Zeiss, Oberkochen, Germany) at x200 or x400 magnification.

Western blot analysis. Total cell lysates were prepared using PRO-PREP protein extraction solution (iNtRON Biotechnology), including $1 \mathrm{mM}$ of sodium orthovanadate, which is an inhibitor of serine/threonine protein phosphatase. Equal amounts $(30 \mu \mathrm{g})$ of samples were resolved by electrophoresis on $10 \%$ SDS-polyacrylamide gels, transferred to a PVDF membrane, and sequentially probed with appropriate antibodies. The primary antibodies were used at a dilution of $1: 1,000$ in $0.1 \%$ TBS-T. This signal was developed with the enhanced chemiluminescence (ECL) detection system (GE Healthcare, Uppsala, Sweden).

RNA interference. The cells were transfected with siRNA specific for Snail-1 (Santa Cruz Biotechnology, Santa Cruz, 
A
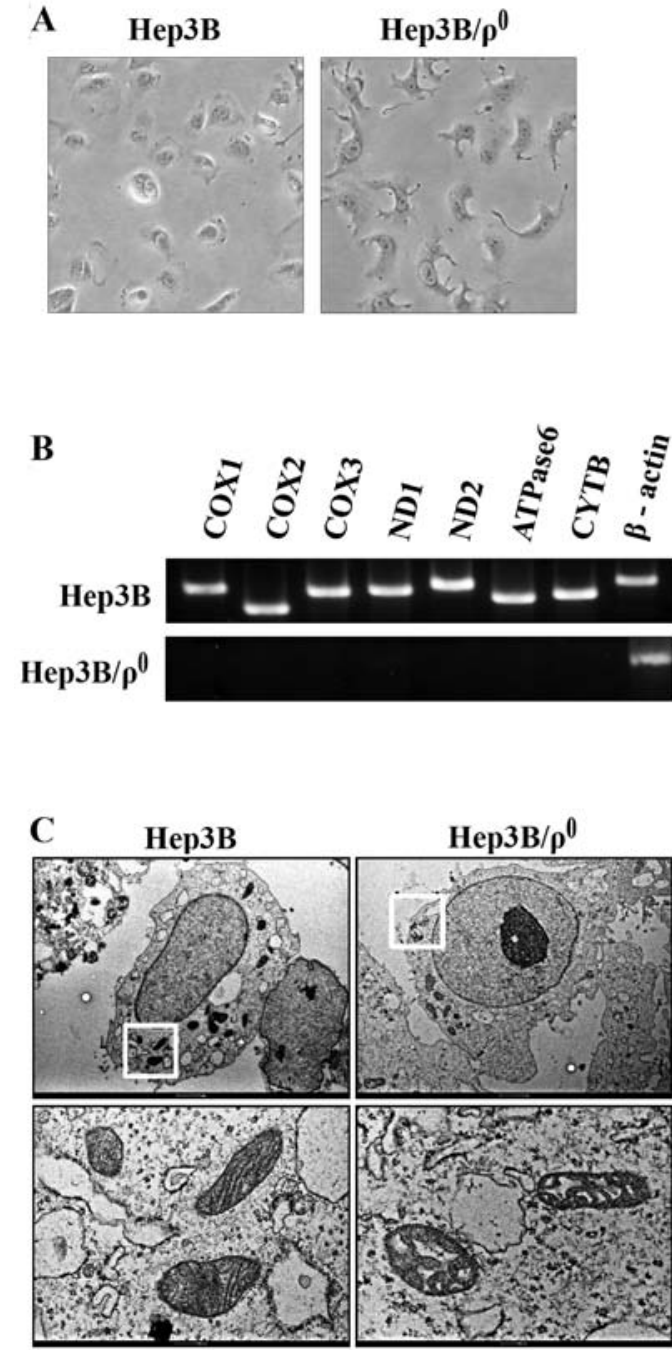

D

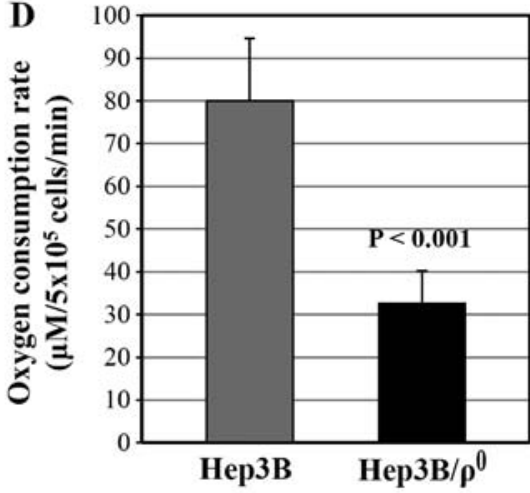

$\mathbf{E}$
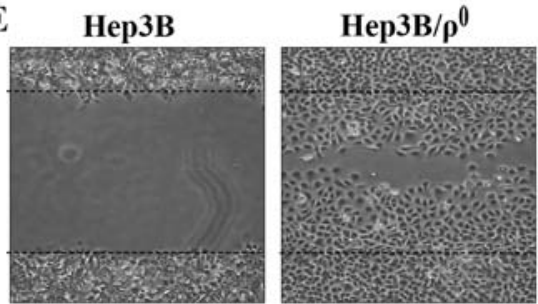

F
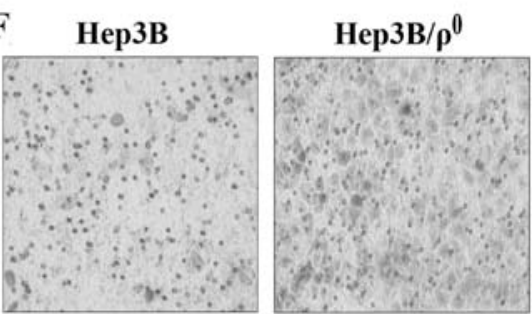

Figure 1. mtDNA-depleted Hep3B $/ \mathrm{Q}^{0}$ cells exhibit the EMT phenotypes. (A) Morphological changes in Hep3B/ $/ \mathrm{Q}^{0}$ cells compared with parent Hep3B cells (B) The conformation of Hep3B $/ \mathrm{e}^{0}$ cells was determined by RT-PCR. The following mtDNA genes were used: COX1, cytochrome $c$ oxidase 1; COX2, cytochrome $\mathrm{c}$ oxidase 2; COX3, cytochrome $c$ oxidase 3; ND1, NADH dehydrogenase 1; ND2, NADH dehydrogenase 2; ATP 6, ATPase 6; CYTB, cytochrome b oxidase. (C) Ultrastructural investigation of wild-type and $\mathrm{Hep} 3 \mathrm{~B} / \mathrm{o}^{0}$ mitochondria by TEM. The lower panel images show higher magnifications of the boxed areas. (D) Oxygen consumption rates $\left(\mu \mathrm{M} / 5 \times 10^{5}\right.$ cells/min) of wild-type and Hep3B/ $/ 0^{0}$ cells (mean $\pm \mathrm{SD}, \mathrm{n}=7$ ). (E) Cell motility was measured by wounding migration assay. (F) In vitro invasion was measured using a Transwell coated with Matrigel. The invaded cells across the Transwell were stained. Changes in cell morphology and activity were examined under a phase-contrast microscope and photographed (magnification, x100).

CA, USA) and control siRNA according to manufacturer's instructions. After transfection, the cells were incubated at $37^{\circ} \mathrm{C}$ for $48 \mathrm{~h}$, and then used for western blot analysis or in vitro wounding migration assay.

Quantification of c-Jun/AP-1 activity. Activity of c-Jun/AP-1 was quantitatively measured by enzyme-linked immunosorbent assay (ELISA) by using commercially available TransAM kits (Active Motif, Carlsbad, CA, USA) following the manufacturer's protocol. For the assay, $20 \mu \mathrm{g}$ of nuclear extract was used. Activated c-Jun/AP-1 levels were specifically detected and quantified using a TransAM AP-1 kit. Active protein-1 (AP-1) dimers in the nuclear extracts bind to specific oligonucleotides containing TPA-responsive elements (TREs) immobilized onto a 96-well plate. Incubation with a c-Jun antibody followed by addition of a secondary antibody conjugated to horseradish peroxidase (HRP) provided sensitive colorimetric readouts that were easily quantified by spectrophotometry $\left(\mathrm{A}_{450 \mathrm{~mm}}\right)$.

\section{Results}

Hep $3 B / Q^{0}$ cells are mtDNA-depleted cell model with EMT phenotypes. To investigate the effects of mitochondrial dysfunction on the EMT process in liver cancer, $\mathrm{Q}^{0}$ cells were first established using the Hep3B hepatocellular carcinoma cell line. To construct $Q^{0}$ cells, Hep3B cells were chronically exposed to ethidium bromide (EtBr) in media. $\mathrm{EtBr}$ preferentially intercalates into mtDNA and leads to depletion of mitochondrial DNA $(10,11)$. mtDNA depletion was first observed by morphological change (Fig. 1A) and was monitored by RT-PCR for mitochondrial gene expression. The mitochondrial gene expressions in $\mathrm{Hep} 3 \mathrm{~B} / \mathrm{Q}^{0}$ cells were substantially reduced, whereas those in parental Hep3B cells amplified at the predicted size (Fig. 1B).

The morphological changes of the $\mathrm{Hep} 3 \mathrm{~B} / \mathrm{Q}^{0}$ mitochondria were confirmed by ultra-structural analysis. Cross-sections through the mitochondrial reticulum in the parental Hep3B cells showed distinct outer and inner membranes with an 
electron-dense matrix full of regularly arranged cristae structures (Fig. 1C; Hep3B). In contrast, the TEM images of the mtDNA-depleted cells showed an apparent alteration of mitochondrial morphology (Fig. 1C; Hep3B/ $\mathrm{Q}^{0}$ ). The network was degraded into single mitochondrial units, often with a swollen appearance.

Subsequently, the absence of respiratory chain activity in $\mathrm{Hep} 3 \mathrm{~B} / \mathrm{Q}^{0}$ cells was confirmed by measuring oxygen consumption (Fig. 1D). The basal oxygen consumption rate was low in $\mathrm{Hep} 3 \mathrm{~B} / \mathrm{Q}^{0}$ cells $\left(32.49 \pm 7.72 \mu \mathrm{M} / 5 \times 10^{6}\right.$ cells $/ \mathrm{min}$, $\mathrm{n}=7$ ), with a mean that is $\sim 59.3 \%$ less than that of Hep3B cells (79.90 $\pm 14.7 \mu \mathrm{M} / 5 \times 10^{6}$ cells $\left./ \mathrm{min}, \mathrm{P}<0.001\right)$. These data confirm that mtDNA depletion in $\mathrm{Hep} 3 \mathrm{~B} / \mathrm{Q}^{0}$ cells is associated with depression of mitochondrial respiratory chain activity.

To examine the migration ability of $\mathrm{Hep} 3 \mathrm{~B} / \mathrm{Q}^{0}$ cells, wounding migration assay was performed. The Hep3B $/ \mathrm{Q}^{0}$ cells migrated substantially, whereas the wild-type cells did not (Fig. 1E). Next, the invasion capacity of $\mathrm{Hep} 3 \mathrm{~B} / \mathrm{Q}^{0}$ cells was examined using a Transwell based invasion assay. The $\mathrm{Hep} 3 \mathrm{~B} / \mathrm{Q}^{0}$ cells were more invasive than the wild-type Hep3B cells (Fig. 1F). These results indicate that mitochondrial dysfunction induces the EMT phenotype by acquiring migration and invasion abilities in the $\mathrm{Hep} 3 \mathrm{~B} / \mathrm{Q}^{0}$ cells.

Hep $3 B / \varrho^{0}$ cells express mesenchymal markers mediated by the TGF- $\beta /$ Smad/Snail signaling pathway. Invasive cell motility is a typical characteristic of mesenchymal cells (12). Therefore, we speculate that $\mathrm{Hep} 3 \mathrm{~B} / \mathrm{Q}^{0}$ cells might have acquired mesenchymal phenotypes. During the EMT process, there is diminished expression of E-cadherin, a marker of epithelial cells, and increased expression of vimentin, a marker of mesenchymal cells (13). As expected, the expression changes of vimentin and E-cadherin showed mesenchymal features. Vimentin in Hep3B $/ \mathrm{Q}^{0}$ cells was highly expressed and E-cadherin was eliminated in both mRNA and protein levels (Fig. 2A and B).

The expression changes in these molecules were then confirmed by immunofluorescence. Parental Hep3B cells exhibited epithelial properties; E-cadherin was expressed on the plasma membrane and there was low vimentin expression (Fig. $2 \mathrm{C}$ and D). In contrast, the Hep3B $/ \mathrm{Q}^{0}$ cells had mesenchymal properties, including increased vimentin in the cytosol and absence of E-cadherin on the plasma membrane (Fig. 2C and D). Because the Hep3B $/ \mathrm{Q}^{0}$ cells originated from epithelial cells, we are able to infer that the epithelial cells transitioned to mesenchymal cells during the course of mitochondrial dysfunction.

In malignant tumors, it is well known that EMT is triggered by growth factors such as TGF- $\beta$ (14). In particular, the EMT marker changes are mainly regulated by TGF- $\beta$ signaling (15). TGF- $\beta$ elicits its cellular responses via TGF- $\beta$ RI and TGF- $\beta$ RII (16). Thus, we examined expression of TGF- $\beta$ and its receptors in the Hep3B/ $\mathrm{Q}^{0}$ cells. The result in Fig. $2 \mathrm{E}$ shows increased expression of TGF- $\beta$ and TGF- $\beta$ RII, which may indicate activation of TGF- $\beta$ signaling in the Hep3B $/ \varrho^{0}$ cells. Upon TGF- $\beta$-induced heteromeric complex formation, TGF- $\beta$ RII phosphorylates TGF- $\beta$ RI. The activated TGF- $\beta$ RI then initiates its intracellular canonical signaling pathway by phosphorylating receptor-regulated Smads such as Smad2 and Smad3 $(17,18)$.
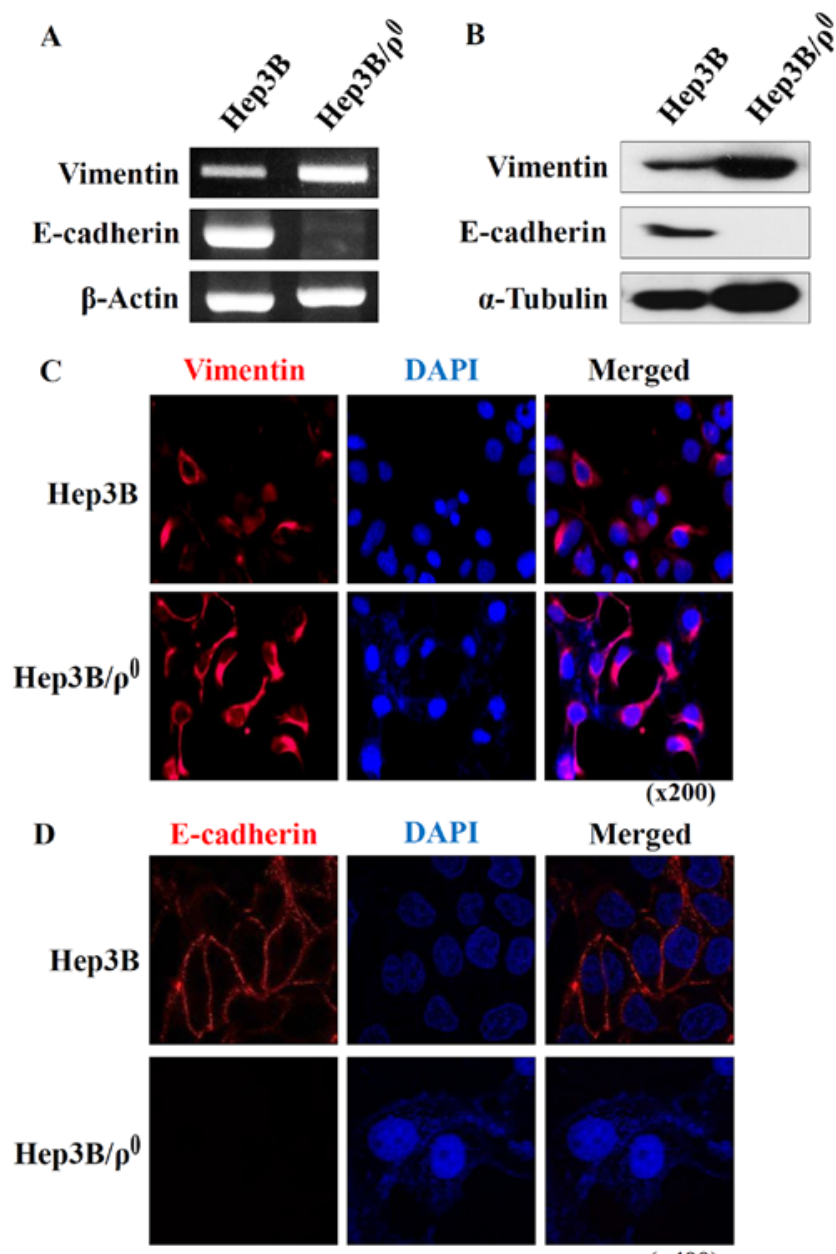

DAPI

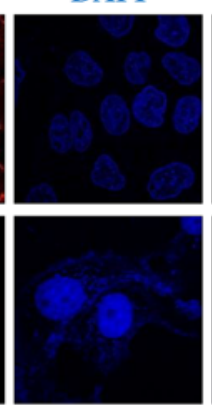

Merged

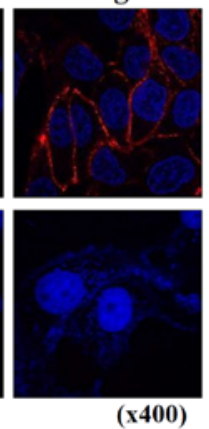

E
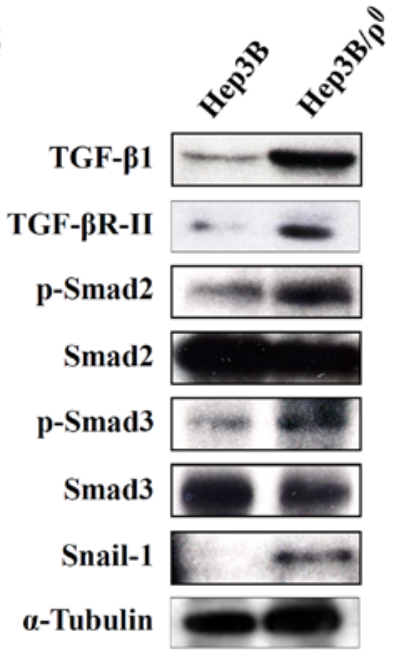

Figure 2. Hep3B $/ \mathrm{Q}^{0}$ cells change expression of EMT markers and are operated by the TGF- $\beta / \mathrm{Smad} / \mathrm{Snail}$ signaling pathway. Total RNA and protein were isolated, and vimentin and E-cadherin expression were examined using (A) RT-PCR and (B) western blot analysis. Immunofluoresence of (C) vimentin and (D) E-cadherin. The indicated cells were stained with anti-vimentin or E-cadherin antibodies. The primary antibodies were visualized by Alexa 488-conjugated secondary antibody. The nuclei were counterstained with DAPI. (E) Total protein was isolated and the expression of TGF- $\beta / \mathrm{Smad} /$ Snail signaling molecules was detected.

To investigate the effect of increased TGF- $\beta$ signaling in the Hep3B/ $\mathrm{Q}^{0}$ cells, the phosphorylation of Smad2 and Smad3 was examined by western blot analysis. Both Smad2 
A
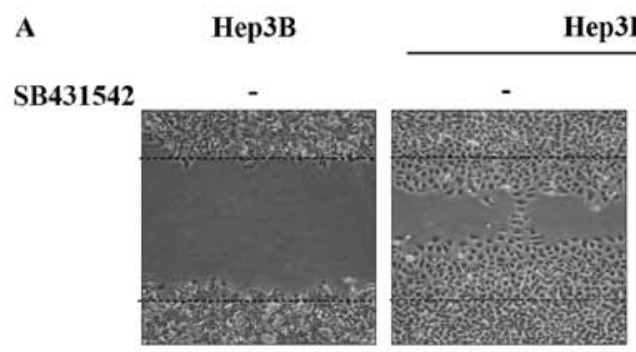

Hep3B $/ \rho^{0}$

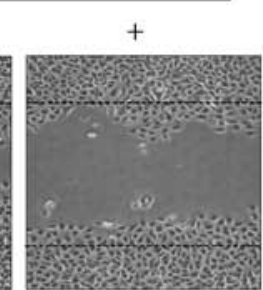

B
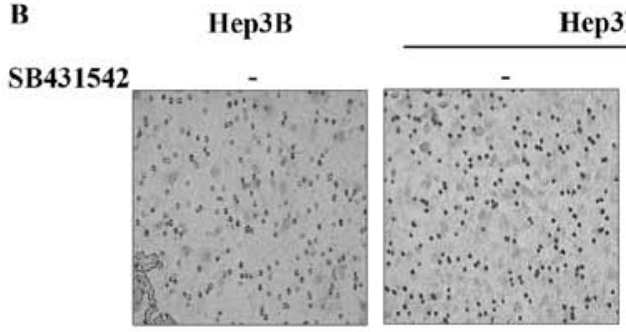

Неp3B/ $\rho^{0}$
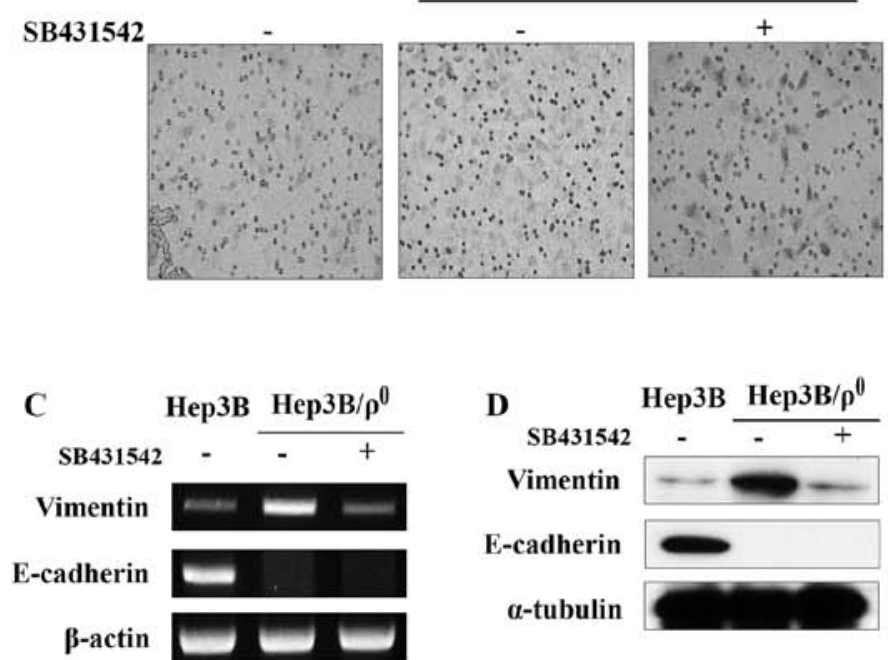

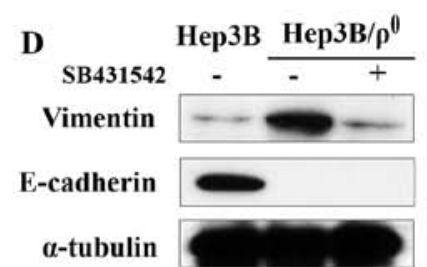

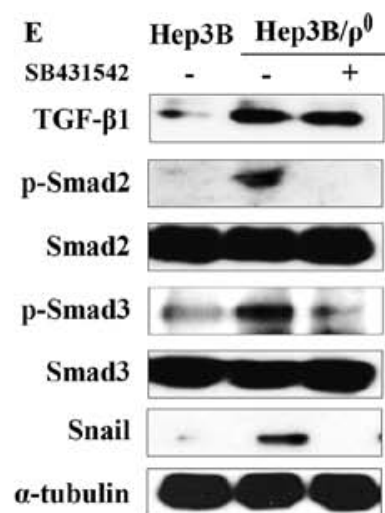

$\mathbf{F}$

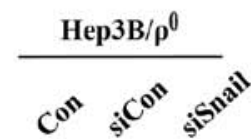

Snail

Vimentin

a-tubulin
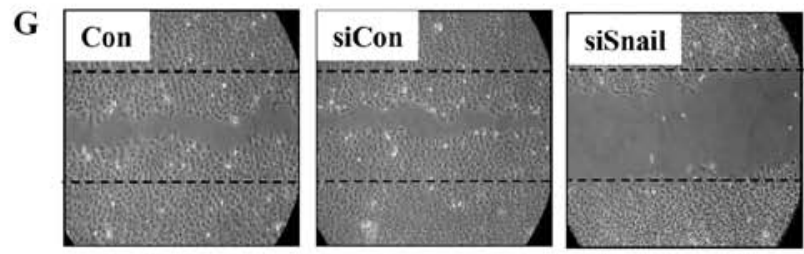

Figure 3. Blockade of TGF- $\beta$ by SB-431542 inhibits EMT phenotypes in Hep3B $/ \mathrm{Q}^{0}$ cells. (A) Motility and (B) invasiveness of cells. After $24-\mathrm{h}$ incubation with or without $2 \mu \mathrm{M}$ of SB-431542, total RNA and protein were isolated and vimentin and E-cadherin expression were examined using (C) RT-PCR and (D) western blot analysis. (E) Inhibition of the TGF- $\beta /$ Smad/Snail signaling pathway was examined by western blot analysis. To confirm these results, additional experiments were conducted using small-interfering RNA. Hep3B/ $0^{0}$ cells were transfected with control siRNA or snail-specific siRNA and incubated for $48 \mathrm{~h}$. (F) Total protein was isolated and the inhibition of Snail and vimentin expression was examined. (G) The transfected cells were seeded and examined by wounding migration assay. Cell activity changes were examined under a phase-contrast microscope and photographed (magnification, x100).

and Smad3 were activated through phosphorylation in the Hep3B $/ \mathrm{Q}^{0}$ cells (Fig. 2E). These activated R-Smads then upregulated the expression of their downstream gene, Snail-1, which is a positive regulator of EMT and metastasis.

Blocking TGF- $\beta$ signaling abolishes EMT phenotypes in Hep $3 B / Q^{0}$ cells. We then determined whether the induced TGF- $\beta$ signaling plays a role on the migration and invasive abilities of the Hep3B $/ \mathrm{Q}^{0}$ cells. SB-431542, a novel small molecule ATP-mimetic inhibitor of kinase activity, was used to inhibit TGF- $\beta$ signaling (19). As expected, SB-431542 potently inhibited the motility and invasiveness of the Hep3B $/ \mathrm{Q}^{0}$ cells (Fig. 3A and B).

SB-431542 also reversed the expression of mesenchymal markers. The increased expression of vimentin in the Hep3B $/ \mathrm{Q}^{0}$ cells was suppressed by SB-431542 in both mRNA and protein levels. Unexpectedly, the expression of E-cadherin was not restored by SB-431542 in either mRNA or protein levels (Fig. 3C and D).

The expression of TGF- $\beta$ and phosphorylation of Smad2 and Smad3 were blocked by SB-431542. Additionally, increased expression of their target gene, Snail, was also reduced (Fig. 3E). These data indicate that EMT phenotypes in the Hep3B $/ \mathrm{Q}^{0}$ cells are mediated by the TGF- $\beta / \mathrm{Smad} / \mathrm{Snail}$ signaling pathway.

The above data indicate that TGF- $\beta$ promotes expression of Snail, which can regulate vimentin expression and malignant phenotypes in the Hep $3 \mathrm{~B} / \mathrm{Q}^{0}$ cells. To provide additional evidence of the key role for Snail in the Hep3B $/ \mathrm{Q}^{0}$ cells, Snail was blocked with siRNA. The Hep $3 \mathrm{~B} / \mathrm{Q}^{0}$ cells were transfected with control or Snail siRNA and incubated for 48 h. Transfection of Snail siRNA significantly blocked Snail expression in the Hep3B $/ \mathrm{Q}^{0}$ cells, whereas transfection of control siRNA had no effect (Fig. 3F). Moreover, vimentin expression was also reduced by blocking Snail expression.

Additionally, to examine the effect of Snail downregulation on the Hep3B $/ \mathrm{Q}^{0}$ cell migration, Hep3B $/ \mathrm{Q}^{0}$ cells were transfected with Snail siRNA. After $48 \mathrm{~h}$ of incubation, an in vitro wounding migration assay was performed with the siRNAtransfected Hep3B $/ \mathrm{Q}^{0}$ cells. Although the control siRNA had no effect on migration, the migration activity was reduced in the Hep3B $/ \mathrm{Q}^{0}$ cells transfected with Snail siRNA (Fig. 3G).

c-Jun/AP-1 activation triggers the TGF- $\beta /$ Smad/Snail signaling pathway and EMT phenotypes in the Hep3B/Q $\varrho^{\circ}$ cells. In previous experiments, we confirmed that the EMT process 
A

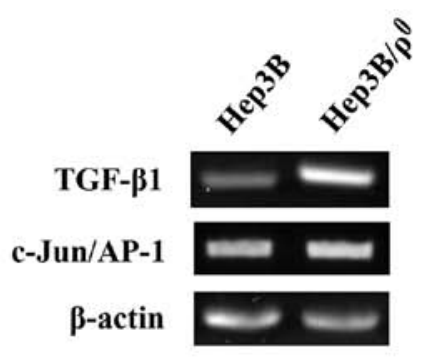

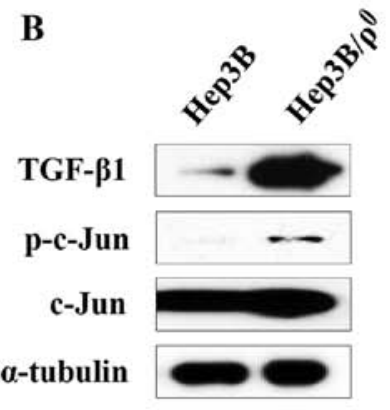

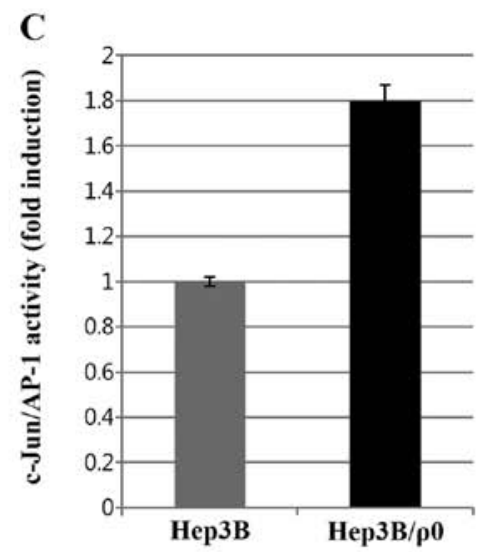

F

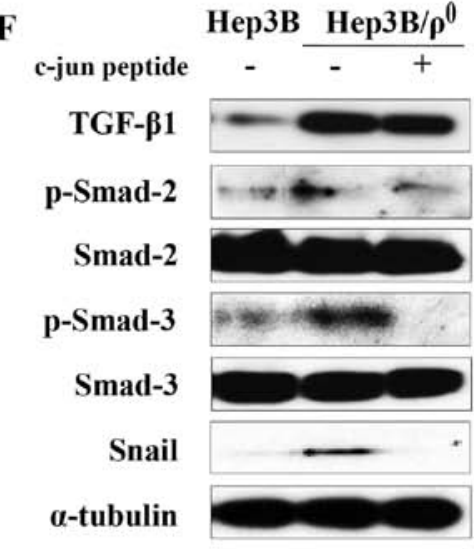

D

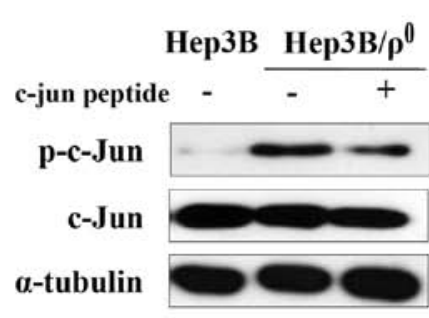

G

c-jun peptide

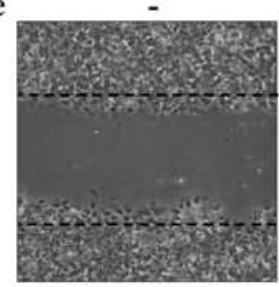

Нер3В

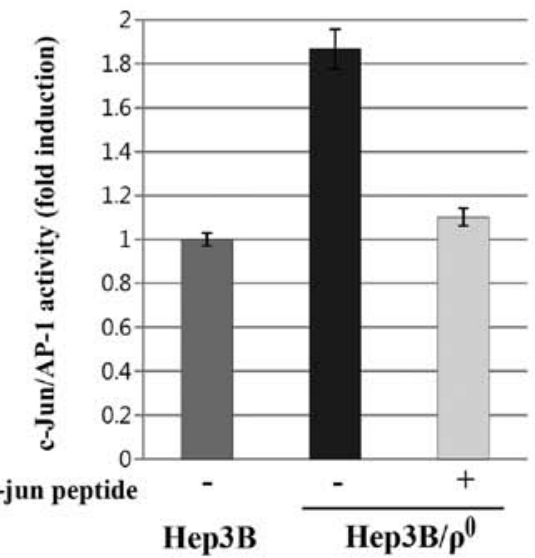

Hep3B $/ \rho^{0}$

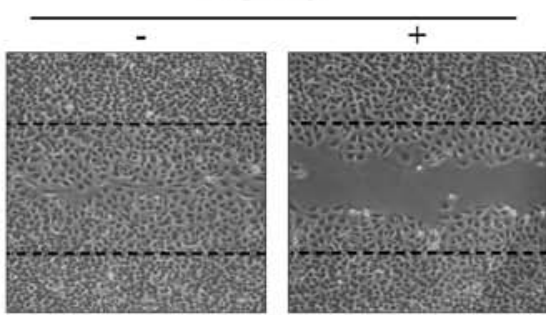

$\mathbf{H}$

c-jun peptide

Нер3В

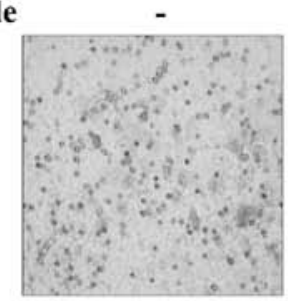

E
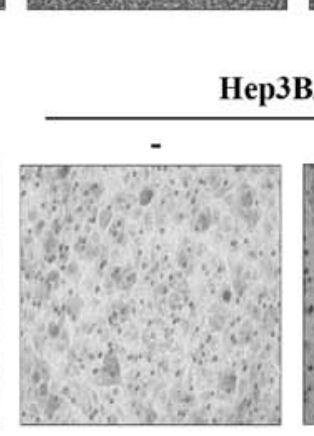

Нер3B $/ \rho^{0}$

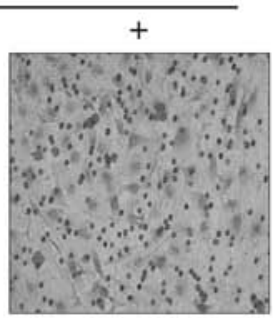

Figure 4. Induction of the TGF- $\beta / \mathrm{Smad} /$ Snail signaling pathway in Hep3B $/ \mathrm{Q}^{0}$ cells mediates c-Jun/AP-1 activation. To examine the cause of TGF- $\beta$ increase, total RNA and protein were isolated, and expression of TGF- $\beta$ and c-Jun/AP-1 phosphorylation were examined using (A) RT-PCR and (B) western blot analysis. After 24-h incubation, nuclear protein was isolated, and (C) c-Jun/AP-1 activity assay was determined. For blockade of c-Jun/AP-1, Hep3B/ $\mathrm{Q}^{0}$ cells were treated with or without $100 \mu \mathrm{M}$ of c-Jun peptide. (D) c-Jun/AP-1 phosphorylation and (E) c-Jun/AP-1 activity were examined. Total protein was isolated and analyzed using (F) western bolt analysis. Additionally, $(\mathrm{G})$ motility and $(\mathrm{H})$ invasiveness of the cells were confirmed. Changes in the cell activity were examined under a phase-contrast microscope and photographed (magnification, x100).

induced by mitochondrial dysfunction occurs through TGF- $\beta /$ Smad/Snail signaling. Several studies have shown that TGF- $\beta$ can be increased by c-Jun/AP-1 activation (20). We examined the expression of c-Jun/AP-1 in order to determine whether c-Jun/AP-1 is involved in the increased TGF- $\beta$ expression by mitochondrial dysfunction in the Hep $3 \mathrm{~B} / \mathrm{Q}^{0}$ cells. We 


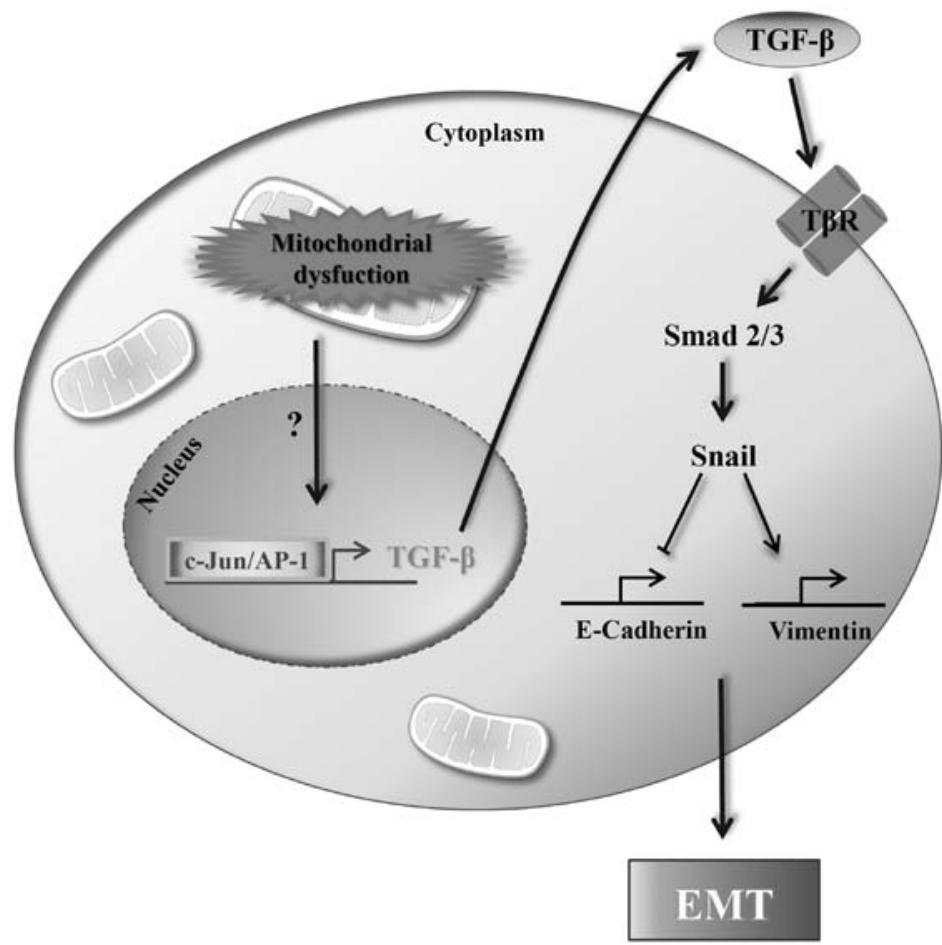

Figure 5. Schematic outline of molecular mechanism on the EMT induction by mitochondrial dysfunction in the Hep3B/ $/ \mathrm{Q}^{0}$ cells.

observed that c-Jun/AP-1 expression was upregulated and c-Jun phosphorylation was increased (Fig. 4A and B). In addition, when we measured the activity of c-Jun/AP-1, we found that c-Jun/AP-1 activity in the Hep3B $/ \mathrm{Q}^{0}$ cells was about two times higher than that in parental cells (Fig. 4C).

We also examined the effect of c-Jun peptide on the expression of c-Jun/AP-1 by adding c-Jun peptide directly to the binding reaction. Phosphorylation of c-Jun was reduced by the c-Jun peptide in the Hep3B $/ \mathrm{Q}^{0}$ cells (Fig. 4D). To further verify these results, we analyzed the effect of c-Jun peptide on c-Jun/AP-1 activation by ELISA. As expected, the c-Jun/AP-1 activity in the Hep3B $/ \mathrm{Q}^{0}$ cells was disturbed by the c-Jun peptide (Fig. 4E).

Then we examined the effect of blocking c-Jun/AP-1 activation by the c-Jun peptide on the TGF- $\beta / \mathrm{Smad} / \mathrm{Snail}$ signaling and EMT phenotypes in the Hep3B $/ \mathrm{Q}^{0}$ cells Expression of the TGF- $\beta$ was reduced by treatment with the c-Jun peptide. Phosphorylation of Smad2 and Smad3 and expression of Snail was also reduced (Fig. 4F). Additionally, blocking of c-Jun/AP-1 activation reduced migration and invasiveness (Fig. 4G and $\mathrm{H}$ ). Taken together, these results suggest that induction of EMT phenotypes by the TGF- $\beta / \mathrm{Smad} / \mathrm{Snail}$ signaling pathway is dependent on c-Jun/AP-1 activation in the Hep $3 \mathrm{~B} / \mathrm{Q}^{0}$ cells.

\section{Discussion}

Cancer cells mainly depend on glycolysis for production of energy they need. Otto Warburg defined the phenotype as 'aerobic glycolysis' and proposed that the glycolytic phenotype of cancer cells could be the result of mitochondrial defects. Recent reports showed point mutations and deletions in mtDNA from a wide range of tumor cells (21-24). In partic- ular, the frequency of mtDNA mutations markedly increased in both non-cancerous and cancerous liver specimens from patients with HCC compared to control liver tissues (2). It was, however, unclear whether these mutations are simply the consequence of increased oxidative stress, known to occur during tumor progression, or they have any direct role in the progression of cancer.

EMT is a mechanism in which epithelial cells differentiate into mesenchymal cells, and it plays an important role in tumor formation and progression to metastatic carcinomas $(25,26)$. During EMT events, epithelial cells lose cell polarity and show spindle-like morphology (27). The EMT process produces distinct features, including disruption of epithelial cell markers, which contain E-cadherin and $\beta$-catenin (28). Furthermore, EMT increases the expression of various mesenchymal markers such as vimentin, $\mathrm{N}$-cadherin, and elevates cell invasion and metastasis (29).

Natio et al (30) reported that mitochondrial depletion could induce EMT by c-Raf/MEK/Erk signaling in breast cancer cells. Thus, we constructed a mitochondrial-depleted cell model with Hep3B to determine the relationship between mitochondrial dysfunction and EMT. In contrast to the parental cells, Hep3B $/ \mathrm{Q}^{0}$ cells are highly migratory and invasive (Fig. 1E and F). The expression pattern of E-cadherin and vimentin also indicates EMT features of the Hep3B $/ \mathrm{Q}^{0}$ cells (Fig. 2A and B).

The TGF- $\beta$ signaling pathway is emerging as an attractive target for cancer treatment (31). Blockade of TGF- $\beta$ signaling may thus be a promising target of therapeutic strategies for advanced cancers. Many studies have demonstrated that blocking of TGF- $\beta$ action by SB-431542 inhibits tumor migration and metastasis (32). The EMT features mediated by TGF- $\beta$ signaling in the Hep3B $/ \mathrm{Q}^{0}$ cells were confirmed 
with SB-431542 treatment. The migration and invasion were inhibited by SB-431542 (Fig. 3A and B). Additionally, increased vimentin expression was reversed by treatment with SB-431542 in the Hep3B $/ \mathrm{Q}^{0}$ cells. During EMT, the expression of E-cadherin is known to be controlled by Snail (33). Thus, we expected that the expression of E-cadherin would be restored by SB-431542. However, contrary to our expectation, the expression of E-cadherin was not restored by SB-431542. As yet, we do not know why the E-cadherin expression was not restored by SB-431542. Other factors in addition to the TGF- $\beta /$ Smad signaling may also be responsible for the reduced expression of E-cadherin in the Hep $3 \mathrm{~B} / \mathrm{Q}^{0}$ cells.

AP-1 has also been implicated in playing a pivotal role during development and carcinogenesis $(34,35)$. The critical role of the c-Jun/AP-1 in the regulation of TGF- $\beta$ expression has been demonstrated in various cells (36). Expression of the c-Jun/AP-1 was reported to be amplified by TGF- $\beta$ during carcinogenesis (37). As shown in Fig. 4, the EMT induction by TGF- $\beta / \mathrm{Smad} / \mathrm{Snail}$ signaling in the Hep3B $/ \mathrm{Q}^{0}$ cells depends on c-Jun/AP-1 activation.

Recently it was reported that mitochondrial retrograde signaling induces EMT in breast cancer cells (38). It was shown that reduction of mtDNA activates the $\mathrm{Ca}^{2+} /$ calcineurin/ Akt-dependent mitochondrial retrograde signaling pathway. Since Akt phosphorylation in the Hep3B/ ${ }^{0}$ cells was rather downregulated (data not shown), there may be more than one mechanism for a mitochondrial dysfunctioned cell to acquire EMT phenotypes.

In conclusion, we demonstrated that the mitochondrial dysfunctioned cell line Hep3B/ $\mathrm{Q}^{0}$, acquired EMT features by activation of the TGF- $\beta / \mathrm{Smad} / \mathrm{Snail}$ signaling pathway (Fig. 5). Collectively, these results indicate that inhibition of TGF- $\beta /$ Smad/Snail signaling under conditions of mitochondrial dysfunction may thus be a potential strategy for therapy of malignant cancers.

\section{Acknowledgements}

The present study was supported by the National Research Foundation of Korea (NRF) Grant funded by the Korean Government (MOE) (no. 2010-0024330) and by the Basic Science Research Program through the National Research Foundation of Korea (NRF) funded by the Ministry of Education (NRF-2013R1A1A2062885) and in part by the Research Fund Program of Genetic Engineering Institute, Pusan National University, Korea, 2015.

\section{References}

1. Brandon M, Baldi P and Wallace DC: Mitochondrial mutations in cancer. Oncogene 25: 4647-4662, 2006.

2. Nishikawa M, Nishiguchi S, Shiomi S, Tamori A, Koh N, Takeda T, Kubo S, Hirohashi K, Kinoshita H, Sato E, et al: Somatic mutation of mitochondrial DNA in cancerous and noncancerous liver tissue in individuals with hepatocellular carcinoma. Cancer Res 61: 1843-1845, 2001.

3. Nomoto S, Sanchez-Cespedes M and Sidransky D: Identification of mtDNA mutations in human cancer. Methods Mol Biol 197: 107-117, 2002

4. Wheelhouse NM, Lai PB, Wigmore SJ, Ross JA and Harrison DJ: Mitochondrial D-loop mutations and deletion profiles of cancerous and noncancerous liver tissue in hepatitis B virusinfected liver. Br J Cancer 92: 1268-1272, 2005.
5. van Zijl F, Zulehner G, Petz M, Schneller D, Kornauth C, Hau M, Machat G, Grubinger M, Huber $\mathrm{H}$ and Mikulits W: Epithelialmesenchymal transition in hepatocellular carcinoma. Future Oncol 5: 1169-1179, 2009

6. Taub R: Liver regeneration: From myth to mechanism. Nat Rev Mol Cell Biol 5: 836-847, 2004.

7. El-Serag HB and Rudolph KL: Hepatocellular carcinoma: Epidemiology and molecular carcinogenesis. Gastroenterology 132: 2557-2576, 2007.

8. Kang Y and Massagué J: Epithelial-mesenchymal transitions: Twist in development and metastasis. Cell 118: 277-279, 2004.

9. Miyazono K, Ehata S and Koinuma D: Tumor-promoting functions of transforming growth factor- $\beta$ in progression of cancer. Ups J Med Sci 117: 143-152, 2012.

10. Chandel NS, Maltepe E, Goldwasser E, Mathieu CE, Simon MC and Schumacker PT: Mitochondrial reactive oxygen species trigger hypoxia-induced transcription. Proc Natl Acad Sci USA 95: 11715-11720, 1998

11. Pelicano H, Feng L, Zhou Y, Carew JS, Hileman EO, Plunkett W, Keating MJ and Huang P: Inhibition of mitochondrial respiration: A novel strategy to enhance drug-induced apoptosis in human leukemia cells by a reactive oxygen species-mediated mechanism. J Biol Chem 278: 37832-37839, 2003.

12. Chaffer CL and Weinberg RA: A perspective on cancer cell metastasis. Science 331: 1559-1564, 2011.

13. Sahai E: Mechanisms of cancer cell invasion. Curr Opin Genet Dev 15: 87-96, 2005.

14. Thiery JP: Epithelial-mesenchymal transitions in tumour progression. Nat Rev Cancer 2: 442-454, 2002.

15. Shi Y and Massagué J: Mechanisms of TGF-beta signaling from cell membrane to the nucleus. Cell 113: 685-700, 2003.

16. Wiercinska E, Naber HP, Pardali E, van der Pluijm G, van Dam $\mathrm{H}$ and ten Dijke P: The TGF- $\beta /$ Smad pathway induces breast cancer cell invasion through the up-regulation of matrix metalloproteinase 2 and 9 in a spheroid invasion model system. Breast Cancer Res Treat 128: 657-666, 2011.

17. Moustakas A and Heldin $\mathrm{CH}$ : The regulation of TGFbeta signal transduction. Development 136: 3699-3714, 2009.

18. ten Dijke P and Hill CS: New insights into TGF-beta-Smad signalling. Trends Biochem Sci 29: 265-273, 2004.

19. Hjelmeland MD, Hjelmeland AB, Sathornsumetee S, Reese ED, Herbstreith MH, Laping NJ, Friedman HS, Bigner DD, Wang XF and Rich JN: SB-431542, a small molecule transforming growth factor-beta-receptor antagonist, inhibits human glioma cell line proliferation and motility. Mol Cancer Ther 3: 737-745, 2004.

20. Sullivan BP, Kassel KM, Manley S, Baker AK and Luyendyk JP: Regulation of transforming growth factor- $\beta 1$-dependent integrin $\beta 6$ expression by $\mathrm{p} 38$ mitogen-activated protein kinase in bile duct epithelial cells. J Pharmacol Exp Ther 337: 471-478, 2011.

21. Nieto MA: The snail superfamily of zinc-finger transcription factors. Nat Rev Mol Cell Biol 3: 155-166, 2002.

22. Han JS, Choi BS, Yang CW and Kim YS: Aldosterone-induced TGF- $\beta 1$ expression is regulated by mitogen-activated protein kinases and activator protein-1 in mesangial cells. J Korean Med Sci 24 (Suppl): S195-S203, 2009.

23. Warburg O, Wind F and Negelein E: The metabolism of tumours. J Gen Physiol 8: 519-530, 1927.

24. Chatterjee A, Mambo E and Sidransky D: Mitochondrial DNA mutations in human cancer. Oncogene 25: 4663-4674, 2006.

25. Kalluri R: EMT: When epithelial cells decide to become mesenchymal-like cells. J Clin Invest 119: 1417-1419, 2009.

26. Cannito S, Novo E, di Bonzo LV, Busletta C, Colombatto S and Parola M: Epithelial-mesenchymal transition: From molecular mechanisms, redox regulation to implications in human health and disease. Antioxid Redox Signal 12: 1383-1430, 2010.

27. Schock F and Perrimon N: Molecular mechanisms of epithelial morphogenesis. Annu Rev Cell Dev Biol 18: 463-493, 2002

28. Thiery JP, Acloque H, Huang RY and Nieto MA: Epithelialmesenchymal transitions in development and disease. Cell 139: 871-890, 2009.

29. Acloque H, Adams MS, Fishwick K, Bronner-Fraser $M$ and Nieto MA: Epithelial-mesenchymal transitions: The importance of changing cell state in development and disease. J Clin Invest 119: 1438-1449, 2009.

30. Naito A, Cook CC, Mizumachi T, Wang M, Xie CH, Evans TT, Kelly $\mathrm{T}$ and Higuchi M: Progressive tumor features accompany epithelial-mesenchymal transition induced in mitochondrial DNA-depleted cells. Cancer Sci 99: 1584-1588, 2008. 
31. Cicchini C, Laudadio I, Citarella F, Corazzari M, Steindler C, Conigliaro A, Fantoni A, Amicone L and Tripodi M: TGFbetainduced EMT requires focal adhesion kinase (FAK) signaling. Exp Cell Res 314: 143-152, 2008.

32. Davies M, Robinson M, Smith E, Huntley S, Prime S and Paterson I: Induction of an epithelial to mesenchymal transition in human immortal and malignant keratinocytes by TGF-betal involves MAPK, Smad and AP-1 signalling pathways. J Cell Biochem 95: 918-931, 2005.

33. Kim SJ, Angel P, Lafyatis R, Hattori K, Kim KY, Sporn MB, Karin $\mathrm{M}$ and Roberts AB: Autoinduction of transforming growth factor beta 1 is mediated by the AP-1 complex. Mol Cell Biol 10 : 1492-1497, 1990

34. Holzberg D, Knight CG, Dittrich-Breiholz O, Schneider H, Dörrie A, Hoffmann E, Resch K and Kracht M: Disruption of the c-JUN-JNK complex by a cell-permeable peptide containing the c-JUN delta domain induces apoptosis and affects a distinct set of interleukin-1-induced inflammatory genes. J Biol Chem 278 : 40213-40223, 2003.
35. Lin WN, Luo SF, Lin CC, Hsiao LD and Yang CM: Differential involvement of PKC-dependent MAPKs activation in lipopolysaccharide-induced AP-1 expression in human tracheal smooth muscle cells. Cell Signal 21: 1385-1395, 2009.

36. Zhang Y, Peng F, Gao B, Ingram AJ and Krepinsky JC: High glucose-induced RhoA activation requires caveolae and PKC $\beta 1$ mediated ROS generation. Am J Physiol Renal Physiol 302: F159-F172, 2012.

37. Lv ZM, Wang Q, Wan Q, Lin JG, Hu MS, Liu YX and Wang R: The role of the p38 MAPK signaling pathway in high glucoseinduced epithelial-mesenchymal transition of cultured human renal tubular epithelial cells. PLoS One 6: e22806, 2011.

38. Guha M, Srinivasan S, Ruthel G, Kashina AK, Carstens RP, Mendoza A, Khanna C, Van Winkle T and Avadhani NG: Mitochondrial retrograde signaling induces epithelialmesenchymal transition and generates breast cancer stem cells. Oncogene 33: 5238-5250, 2014. 